\title{
Separation Behaviour of Iron Ore Fines in Kelsey Centrifugal Jig
}

\author{
Nirlipta P. Nayak ${ }^{*}$, Bhatu K. Pal \\ Department of Mining Engineering, National Institute of Technology, Rourkela, India \\ Email: "nirliptanayak@rediffmail.com
}

Received February 22, 2013; revised March 26, 2013; accepted April 5, 2013

Copyright (C) 2013 Nirlipta P. Nayak, Bhatu K. Pal. This is an open access article distributed under the Creative Commons Attribution License, which permits unrestricted use, distribution, and reproduction in any medium, provided the original work is properly cited.

\begin{abstract}
Kelsey Centrifugal Jig was found to be promising for the beneficiation of fine iron particles. The present study was carried out to have a better understanding of the separation process of Kelsey Jig through detailed experimentation. Beneficiation of fine iron ore fines was studied in Kelsey Jig. A constant pulp density (25\% solids) of the feed slurry was maintained in the study. The feed rate was also kept constant at $60 \mathrm{~kg} / \mathrm{hr}$ (dry solids basis). Magnetite of size $-0.853+$ $0.6 \mathrm{~mm}$ was used as ragging material to avoid the pegging of internal screen having an opening of $425 \mu \mathrm{m}$. The rotational speed was found to have significant effect on the depth of the ragging bed and its porosity. Pulsation was identified as the key factor in stratifying the iron bed and defining the misplacement as well as ragging bed porosity, influencing the mass yield and quality of product.
\end{abstract}

Keywords: EGS; Ragging Material; Beneficiation

\section{Introduction}

Mechanized mining operation along with its multiple advantages brought drastic changes in the ROM iron quality by increasing the fines and dirt. Surface propertybased separation processes such as froth flotation and agglomeration are very selective in rejecting well-liberated mineral matters. However, efficiency of these processes gets reduced if the feed contains disproportionate amount of composite particles. Surface based separation processes are very intricate, needs close attention and careful operation where as the conventional gravitybased separation techniques like spiral concentrator, water only cyclone or dense media cyclone have all been found to be inefficient for treating ultra fine particles in terms of selectivity and recovery [1].

The new genre of enhanced gravity separators overcome the problems associated with the surface-based separation processes as well as conventional gravity processes. A Falcon Concentrator is a spinning fluidized bed concentrator, which is a combination of sluice and continuous centrifuge [2]. It enables the treatment of particles in the size range of $15-20 \mu \mathrm{m}$. The Knelson Concentrator is a compact centrifugal separator with an ac-

"Corresponding author. tive fluidized bed to capture the heavy minerals. It can treat particles ranging in size from $10 \mu \mathrm{m}$ to a maximum of $2 \mathrm{~mm}$. The multi-gravity separator combines the centrifugal motion of an angled rotating drum with the oscillating motion of a shaking table to provide an enhanced gravity separation of the fine particles [3]. The Kelsey Centrifugal Jig (KCJ) works on the separation principles of a conventional jig employing a centrifugal force field. A much higher G-force $(80$ - $100 \mathrm{G})$ is obtained enabling the treatment of particles between 5 and $500 \mu \mathrm{m}$.

The major advantage of enhanced gravity separation is its ability to reject composite particles more efficiently than flotation [4]. Among the enhanced gravity separators, the KCJ is very promising due to its higher production capacities and utilization of less plant area. The KCJ is successfully demonstrated for the concentration of tin, mineral sand, gold, platinum ores and iron ore slime.

\section{Principle of Enhance Gravity Separators}

Settling velocity of an individual particle is determined from its physical properties such as shape, size and density along with the fluid-particle \& particle-particle interactions. Particle dynamics may be expressed as follows: 


$$
m^{p} d u^{p} / d t^{p}=F^{g}-F^{b}-F^{d}
$$

where $\mathrm{m}$ and $\mathrm{u}^{\mathrm{p}}$ are the mass and velocity of a particle respectively. $\mathrm{t}$ is the time, $\mathrm{F}^{\mathrm{g}}, \mathrm{F}^{\mathrm{d}}, \mathrm{F}^{\mathrm{b}}$ are the gravitational force, drag force and buoyant force acting upon the particle respectively. Particles having higher specific gravity settle faster than those having lower specific gravity and thus differential mobility is generated. For better separation, a minimum difference in settling velocity between two minerals is essential. To ensure a minimum difference in settling velocity concentration criterion is described as follows.

$$
\mathrm{C}^{\mathrm{c}}=\frac{\rho^{\mathrm{h}}-\rho^{\mathrm{m}}}{\rho^{1}-\rho^{\mathrm{m}}}
$$

where $\rho^{\mathrm{h}}, \rho^{1}, \rho^{\mathrm{m}}$ are the specific gravity of heavy mineral, light mineral and fluid respectively and $\mathrm{C}^{\mathrm{c}}$ is the concentration criteria. $\mathrm{C}^{\mathrm{c}}$ above 2.5 gives notable separation in conventional gravity separators where as EGSs systems are capable of separation below 2.5. In EGSs, gravity is enhanced by application of centrifugal field to cause economic separation. The settling velocity of a particle in a centrifugal field can be expressed as follows.

$$
\mathrm{m}^{\mathrm{p}} \mathrm{du}^{\mathrm{pr}} / \mathrm{dt}=\mathrm{F}^{\mathrm{c}}-\mathrm{F}^{\mathrm{b}}-\mathrm{F}^{\mathrm{d}}
$$

where $\mathrm{u}^{\mathrm{pr}}$ is the particle radial velocity and $\mathrm{F}^{\mathrm{c}}$ is the centrifugal force acting on the particle. Under steady condition, particles settling in Stokes flow regime under centrifugal field could be expressed as follows.

$$
\mathrm{u}^{\mathrm{pr}}=\left(\rho^{\mathrm{p}}-\rho^{\mathrm{f}}\right) \mathrm{d}^{2} \mathrm{p} \omega^{2} \mathrm{r} / 18 \mu
$$

where $\rho^{\mathrm{p}}$ and $\rho^{\mathrm{f}}$ are particle and fluid density respectively, $\omega$ is particle angular velocity, $\mathrm{r}$ is the radius of circulatory motion, $\mathrm{d}$ is the diameter and $\mu$ is the fluid viscosity. The enhancement of settling velocity is the fundamental of EGSs.

Lump and fines ratios in Indian iron ore deposits are almost 50:50 (as shown in Figure 1) but only 12.3\% of these reserves belong to high grade category while $48 \%$ belong to medium grade, $26 \%$ to low grade and rest to unclassified categories [5]. Iron ore, range in size from less than $8 \mathrm{~mm}$ to $0.15 \mathrm{~mm}$ are designated as fines, whereas, the ore below $0.15 \mathrm{~mm}$ are known as slime [6] and slimes are generated in the washing plant. Unless fines find an outlet directly or through conversion into sinters/pellets, these will go on accumulating at mine sites.

While reports of the application of the KCJ are plentiful, literature on the fundamentals of separation behavior are very limited. The impact of the operating variables and the reasons for such influence, the guidelines for selecting the ragging material, etc., are unavailable. The complex interaction of the various forces and the net effect of them are not clearly understood. The effect of the spin frequency and pulsation rate on the separation proc- ess and the reason behind was investigated.

\section{Relevant Principle of Operation}

The Kelsey jig is an appropriate substitute to the conventional jig with some basic similarities. The parameters of conventional jig are entirely utilized along with additional features to vary the apparent gravitational field. The ability to increase the apparent gravitational field enhances the chances of recovery of fine particles by improving their settling characteristics.

The KCJ is fed down a fixed central pipe and the feed slurry is distributed at the bottom of the bowl, which flows upwards over the surface of a bed of ragging material supported by a cylindrical screen. The screen is spun coaxially with the rotor and pressurized water is introduced into a series of hutches behind the screen [7]. Water is pulsated through the ragging bed, which helps in stratifying the feed as well as dilating the ragging bed. Particles with specific gravity greater than or equal to that of the bed of the ragging material pass through the ragging bed. The principles of differential acceleration hindered settling, and interstitial trickling hold [8]. The differential acceleration rates are substantially enhanced by the higher apparent gravitational forces arising out of the rotation. The denser particles pass through the internal screen to concentrate hutches and then through spigots to a concentrate launder. The lighter particles are swept away by the rising flow and are discharged over a ragging retention ring into the tailing launder as shown in Figure 2.

\section{Unit Operation}

A laboratory Kelsey Jig (Model No. J200 supplied by Roche Mining) was used in the study. A lean grade iron ore fine sample from Eastern India (Bonai-Keonjhar belt) was taken up for the study. The chemical analysis of the bulk sample presented in Table 1. The separation efficiency of the KCJ depends upon several factors which

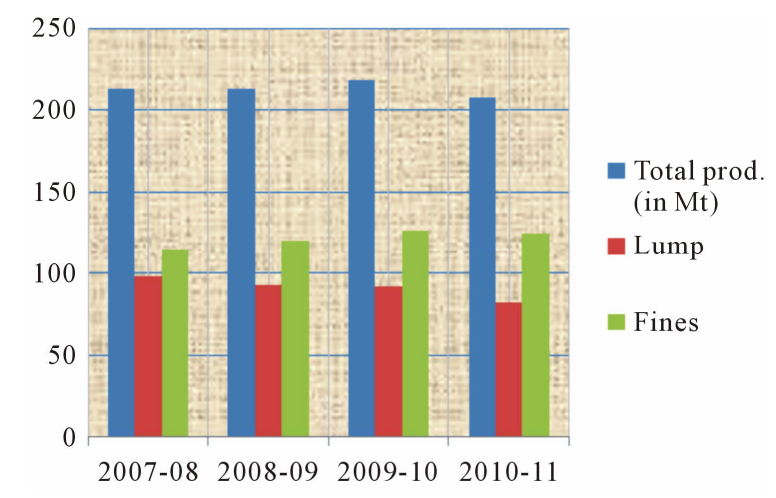

Figure 1. Iron ore production (Lump/fines) in India from 2007-2011. 


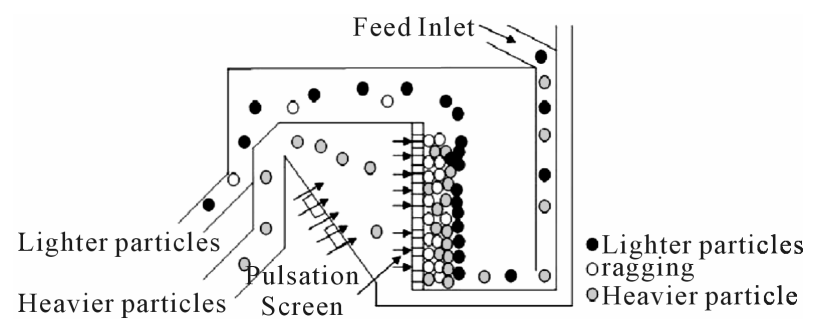

Figure 2. Partial cross-section of Kelsey Jig (source: IMPC, 2012).

Table 1. Chemical analysis of iron ore fines.

\begin{tabular}{cccc}
\hline $\mathrm{Fe}(\%)$ & $\mathrm{SiO}_{2}(\%)$ & $\mathrm{Al}_{2} \mathrm{O}_{3}(\%)$ & LOI \\
\hline 54.47 & 12.86 & 4.03 & 6.42 \\
\hline
\end{tabular}

include the spin frequency, pulsation frequency, the nature of ragging material and the ragging bed thickness, the feed flow rate, hutch water addition as well as the screen opening. The interaction among these factors is very complex in nature which renders the process extremely difficult to describe from a theoretical standpoint. The influences of spin frequency, pulsation frequency were investigated. The other operating variables were kept constant during the experimental work. The feed rate was maintained at $60 \mathrm{~kg} / \mathrm{hr}$ (dry solid basis). A screen with 425 micron opening (internal aperture) was used and magnetite was used as the ragging material. The size of the magnetite was taken as $0.853+0.6 \mathrm{~mm}$. The hutch water flow rate was maintained at $25 \mathrm{~L} / \mathrm{min}$ under all experimental conditions.

\section{Materials}

To nullify the effect of feed size on the separation efficiency, mono-sized iron particles were used in this study. The feed to the KCJ was screened at a size less than the internal screen size to avoid pegging. In the present study, iron ore of size $<300$ micron were used as feed material. The particle size of the ragging material to be used depends on the pegging factor of the internal screen. Pegging factor is the ratio of internal screen aperture to the bottom size of the ragging material. It is recommended that for smooth operation pegging factor should be close to 0.6. Based on this, the minimum permissible size of the ragging material was estimated at 708 micron. Therefore, the minimum particle size of the ragging material used in this study was 850 micron.

\section{Methods}

Magnetite of size 850 micron was fed through a central pipe and was distributed over the cylindrical screen by the rotation of the bowl. Feed pulp having 25\% dry solids (Iron) by weight was fed through the central pipe. Hutch water was pulsated at a pressure of $500 \mathrm{kPa}$ to stratify the feed material. Once the steady state was achieved, the heavier and lighter products were collected through concentrate and tailing launders, respectively. Subsequently, these were dried, weighed, and analyzed for iron. Number of experiments was carried out to study the effect of spin rpm, pulsation rate on the separation performance. The ragging bed was formed by introducing the magnetite and the time was noted after which no magnetite particles came out. Once the bed was formed, the feed slurry was introduced at the desired rate through a peristaltic pump. Once the process variables were set, the system was allowed to run for 10 - 15 minutes to achieve steady state. The samples were then collected and processed to generate the performance data. The results of these experiments in terms of product yield and grade are shown in Table 2.

The weight of ragging material (300 gms) was kept constant throughout the entire operation.

Feed Rate: $60 \mathrm{~kg} / \mathrm{hr}$.

Six numbers of tests were performed under varying conditions listed below (Table 2).

\section{Result \& Discussion}

The $\mathrm{Fe} \%$ obtained in the above set of experiments is in the range of $59 \%-65 \%$ in compared to $54.4 \% \mathrm{Fe}$ in the feed. The result thus is quite encouraging. The results clearly indicate that by changing the operating variables, it is possible to get a better concentrate or clear reject.

The two operating variables include:

1) Bowl Rotation/spin frequency (rpm);

2) Bed Pulsation.

Spin frequency is the rotational speed of the bowl or in other words it is the centrifugal force acting upon the flow pattern inside the jig. It affects the behavior of ragging bed as well as particle momentum.

The spin frequency has two contradictory effects:

i) When spin is increased, there is an increase in gravitational force acting upon the ragging bed which in turn becomes more compact and rendering it less porous. As a result very limited quantity of material will penetrate the ragging bed results a decrease in yield but a high grade concentrate. It is inferred from Test-2 \& 3 , where at a higher frequency there is a drop in yield from 49.05 to 46.70 with an increase in grade from 62.71 to 65.90 ;

ii) With increase in spin frequency, the centrifugal force acting upon the particles increases. It leads to increase in particle momentum which increases the probability of passage of more particles trough the ragging bed. In this condition, there is an increase in yield of concentrate but dilution of grade happened. This can be inferred from Test-1 \& 2 and Test-1 \& 3. In case of Test-1 \& 2, with increase in frequency from 590 to 600 , 
Table 2. Experimental results under different operating conditions.

\begin{tabular}{|c|c|c|c|c|c|c|c|}
\hline \multicolumn{8}{|c|}{ Experimental condition } \\
\hline No of tests & Bowl rotation & Pulsation & Ragging weight & Feed rate $(\mathrm{kg} / \mathrm{hr})$ & Product & Yield\% & $\mathrm{Fe} \%$ \\
\hline \multirow{2}{*}{1} & \multirow{2}{*}{600} & \multirow{2}{*}{1000} & \multirow{2}{*}{300} & \multirow{2}{*}{60} & Conc. & 61.73 & 59.47 \\
\hline & & & & & Tail & 38.27 & 46.20 \\
\hline \multirow[b]{2}{*}{2} & \multirow[b]{2}{*}{590} & \multirow[b]{2}{*}{1000} & \multirow[b]{2}{*}{300} & \multirow[b]{2}{*}{-} & Conc. & 46.7 & 65.90 \\
\hline & & & & & Tail & 53.3 & 45.05 \\
\hline \multirow{2}{*}{3} & \multirow{2}{*}{580} & \multirow{2}{*}{1000} & \multirow{2}{*}{300} & \multirow{2}{*}{60} & Conc. & 49.05 & 62.71 \\
\hline & & & & & Tail & 50.95 & 46.01 \\
\hline \multirow[b]{2}{*}{4} & \multirow{2}{*}{580} & \multirow{2}{*}{970} & \multirow{2}{*}{300} & \multirow{2}{*}{60} & Conc. & 52.42 & 61.81 \\
\hline & & & & & Tail & 47.58 & 45.70 \\
\hline \multirow{2}{*}{5} & \multirow{2}{*}{590} & \multirow{2}{*}{970} & \multirow{2}{*}{300} & \multirow{2}{*}{60} & Conc. & 59.62 & 59.31 \\
\hline & & & & & Tail & 40.38 & 47.09 \\
\hline \multirow{2}{*}{6} & \multirow{2}{*}{550} & \multirow{2}{*}{980} & \multirow{2}{*}{300} & \multirow{2}{*}{60} & Conc. & 57.15 & 63.59 \\
\hline & & & & & Tail & 43.85 & 42.09 \\
\hline
\end{tabular}

there is a sharp rise in yield from $46.7 \%$ to $61.73 \%$ with Fe percentage decreases from $65.9 \%$ to $59.47 \%$. More or less similar relation is observed in Test- 1 \& 3 .

By virtue of density, high density particles remain close to the ragging bed and vice-versa, but the particles with intermediate density (goethite) decide the efficiency of separation as they may increase/decrease the yield there by affecting the concentrate grade.

3) Pulsation: Pulsating strokes dilates the ragging bed thereby facilitating the movement of particles trough the bed material. In high pulsating condition, particles are prevented from attaining terminal velocity. Thus the differential acceleration between light and heavy particle is maintained. Pulsation stokes are more profound on lighter material. So probability of migration of lighter elements into concentration stream is feeble resulting low yield \& high concentrate grade which is reflected in Test- $3 \& 4$.

In high pulsation condition, the time difference between dilation and contraction get reduced, results sluggish movement of particles. As a result less quantity of material will penetrate decreasing the yield. It can be verified comparing Test- $5 \& 2$.

Test No-6 sows the best result with $550 \mathrm{rpm} \& 980$ Bed pulsations i.e. in low rpm and intermediate pulsation condition.

\section{Conclusions}

Kelsey centrifugal jig is found to be as a promising advanced gravity separator for low grade iron ore fines. By controlling the process variables, there is ample scope for achieving a high yield. Best results are obtained in low rotational speed and moderate pulsation condition.

Spin frequency affects the porosity of the ragging bed as well as the momentum of the particles. It is established in the present work how the spin frequency needs to be controlled in order to achieve the target mass yield and grade of the products. The pulsation also has been shown to have significant influence on the porosity of the ragging bed as well as the differential acceleration of the particles. A high clean coal yield can be achieved through a high pulsation frequency. However, in order to get the best results a moderate level of pulsation is recommended.

\section{REFERENCES}

[1] A. Bandopadhyay, "Multi-Gravity Separator-Equipment for Separation of Fines," Processing of Fines, Vol. 2, 2000, pp. 81-92.

[2] B. Sarkar, S. Chandra and A. Das, "Advanced Gravity Separators-A Review of State of the Art Technology," Proceedings of National Seminar on Advanced Gravity Separator, Jamshedpur, 2007, pp. 57-74.

[3] Pradip, "Processing of Alumina-Rich Indian Iron Ore Slimes," International Journal of Mineral, Metals and Materials Engineering, Vol. 59, No. 5, 2006, pp. 551568.

[4] B. A. Wills and T. Napier-Munn, "Mineral Processing Technology," Elsevier Science \& Technology Books, 2006.

[5] S. Roy, A. Das and M. K. Mohanty, "Feasibility of Producing Pellet Grade Concentrate by Beneficiation of Iron Ore Slimes in India," Separation Science \& Technology, Vol. 42, No. 14, 2007, pp. 3271-3287. 
doi:10.1080/01496390701514824

[6] N. P. Nayak, A. Das and B. K. Pal, "Characterization Driven Processing of Indian Iron Ore Slime," Accepted in International Journal of Research in Chemistry and Environment, 2013.

[7] R. K. Singh and A. Das, "Study of Separation Features of
Fine Coal Cleaning in Kelsey Centrifugal Jig," 26th International Mineral Processing Congress, New Delhi, September 2012, pp. 5047-5056.

[8] P. Tucker, "Modeling the Kelsey Centrifugal Jig," Mineral Engineering, Vol. 8, No. 3, 1995, pp. 333-336. 